\title{
Effectiveness of Two Desensitizer Materials, Potassium Nitrate and Fluoride Varnish in Relieving Hypersensitivity After Crown Preparation
}

\author{
Azadeh Abdollahi ${ }^{1}$, Ezzatollah Jalalian ${ }^{2}$
}

\begin{abstract}
Aim: The aim of this clinical investigation was to compare the efficacy of fluoride varnish and potassium nitrate on the reduction of hypersensitivity of prepared teeth both pre and post cementation.

Materials and methods: In this randomized clinical trial, patients who needed at least three single crowns fixed partial prosthesis were included. Two desensitizing agents including fluoride varnish and potassium nitrate were used in this study and compared to the control group (sterile saline). In each patient, each prepared tooth was randomly assigned to one group. The desensitizing agent was applied on prepared teeth immediately after tooth preparation. The sensitivity of the teeth was measured by means of an air sensitivity test based on the visual analog scale at five different time points: baseline ( 2 hours after preparation), 7 days after preparation, before cementation, after cementation and one-week post cementation. Data were analyzed by Kruskal-Wallis and Friedman tests with a significant level of 0.05 .

Results: Overall 300 vital abutment teeth needed full crown coverage in 100 patients were included. Both desensitizers' agents decreased the sensitivity of vital abutment teeth compared to the control group at every time intervals except at baseline $(p=0.089)$. There was no significant difference between fluoride varnish and potassium nitrate in the reduction of pre-cementation sensitivity while one week after cementation, sensitivity was more relieved by potassium nitrate compared to fluoride varnish $(p=0.023)$.

Conclusion: The application of both desensitizers is effective in sensitivity reduction of vital abutment teeth. Potassium nitrate, however, is more eligible one week after cementation compared to fluoride varnish.

Clinical significance: Both potassium nitrate and fluoride varnish are capable of desensitizing prepared tooth for the fixed partial denture.

Keywords: Fixed prosthodontics, Fluoride varnish, Hypersensitivity, Potassium nitrate, Vital tooth preparation.

The Journal of Contemporary Dental Practice (2019): 10.5005/jp-journals-10024-2544
\end{abstract}

\section{INTRODUCTION}

$\mathrm{T}^{+}$ ooth hypersensitivity is characterized by an ambiguous (nonspecific) or specific, intermittent or continuous transient and sharp pain originated from exposed dentin in response to external stimulations such as chemical, thermal, osmotic, dehydrating or tactile stimuli. ${ }^{1,2}$ Clinical experiences show that most of the patients report hypersensitivity after preparation of vital teeth for the fixed prosthesis, which is probably due to the connection between external environment and dental pulp that causes the movement of intratubular fluid and the stimulation of pulpal nerve. ${ }^{2}$ The removal of enamel and reduction of dentin thickness which occur during tooth preparation result in an increase in the amount of dentin permeability and pulp irritability. By crown preparation, approximately 1-2 million dentinal tubules are exposed and it increases the possibility of sensitivity. ${ }^{3}$ A host of theories have sought to explain tooth hypersensitivity. Today the most widely accepted theory on tooth hypersensitivity is the hydrodynamic theory. This theory suggests that a rapid change in tubular fluid flow in response to various stimuli results in stimulated bar receptors and, consequently, the nerves become depolarized. ${ }^{4}$

It has been reported that $15 \%$ of prepared teeth for fixed prosthodontics become sensitive ${ }^{5,6}$ while in about $5 \%$ of the cases necrosis of the pulp occurs. ${ }^{7}$ An alternative treatment for hopeless teeth is to restore with dental implants ${ }^{8,9}$ which sometimes needs bone grafting and alveolar reconstruction. ${ }^{10-13}$

The relief of tooth hypersensitivity could be achieved by either natural or therapeutic desensitization. Hypersensitivity mainly
'UT Health Dental School, San Antonio, Texas, USA; Department of Kinesiology and Health, and Nutrition, University of Texas, San Antonio, United States

${ }^{2}$ Department of Prosthetic Dental Science, College of Dentistry, King Saud University, Riyadh, Kingdom of Saudi Arabia

Corresponding Author: Ezzatollah Jalalian, Department of Prosthetic Dental Science, College of Dentistry, King Saud University, Riyadh, Kingdom of Saudi Arabia, Phone: +989123238296, e-mail: dr_e_ jalalian@yahoo.com

How to cite this article: Abdollahi A, Jalalian E. Effectiveness of Two Desensitizer Materials, Potassium Nitrate and Fluoride Varnish in Relieving Hypersensitivity After Crown Preparation. J Contemp Dent Pract 2019;20(4):489-493.

Source of support: Nil

Conflict of interest: None

decreases with time due to the tooth natural desensitization process. Salivary proteins cover the outer surface and plasma proteins cover the inner surface of dentin, and they seal the dentin tubules. ${ }^{14}$

Therapeutic desensitization methods for alleviation of tooth hypersensitivity include sealing the dentinal tubules by using materials such as lons, salts, dentin sealer, and protein deposition, nerve depolarization prevention by using substances such as Potassium nitrate, the use of anti-inflammatory drugs, and gingival grafts. ${ }^{15-19}$

Varnish fluoride is usually applied on tooth surface (especially on demineralized surfaces) to prevent or arrest dental caries. In

(O) The Author(s). 2019 Open Access This article is distributed under the terms of the Creative Commons Attribution 4.0 International License (https://creativecommons. org/licenses/by-nc/4.0/), which permits unrestricted use, distribution, and non-commercial reproduction in any medium, provided you give appropriate credit to the original author(s) and the source, provide a link to the Creative Commons license, and indicate if changes were made. The Creative Commons Public Domain Dedication waiver (http://creativecommons.org/publicdomain/zero/1.0/) applies to the data made available in this article, unless otherwise stated. 
addition, it has been demonstrated that fluoride varnish by sealing dentin tubules prevents tubal fluid flow and causes a decrease in tooth hypersensitivity. ${ }^{20,21}$ This material exerts its desensitizing property very fast, and its application is easy and cost-effective as well. ${ }^{22}$

Unlike other desensitizing materials, Potassium Nitrate is a substance which does not seal the tubules. It affects dental nerves and increases the nerve stimulation threshold directly by raising extracellular $\mathrm{K}^{+}$concentration ${ }^{18}$ and prevents the entrance of sodium ions into the nerve and stop nerve repolarization (action potential). In addition, potassium causes vasodilatation and decrease neuropeptides such as calcium gene-related peptide (CGRP) release in response to pulpal nerve stimulation. So a stronger stimulus is needed to transmit nerve messages. ${ }^{23}$

Previous studies demonstrated the ability of potassium nitrate and sodium fluoride in the reduction of tooth sensitivity. 2,20,24-26 None of these two materials had superiority for the treatment of tooth hypersensitivity. ${ }^{22,27}$ As following vital tooth crown preparation, the dentinal tubules are exposed, desensitizing materials might show a different ability compared to the case of none prepared hypersensitive teeth. It is the clinician's job to predict the sequence of treatment outcome. ${ }^{28}$ Randomized clinical trials are necessary for evidence-based clinical decision making. ${ }^{29}$ Hence, the aim of the current study was to evaluate and compare the efficacy of potassium nitrate and fluoride varnish in reducing the sensitivity of vital prepared teeth for fix partial denture (FPD) abutment.

\section{Materials AND methods}

This study was conducted as a double-blind Paired Parallel Design Randomized Controlled Trial according to CONSORT 2010. The study protocol was approved by the ethical committee of Islamic Azad University, Iran. The patients included were given full information and signed informed consent. Patients were recruited from those who referred to the dental branch of Islamic Azad University, Iran in 2016.

The inclusion and exclusion criteria for the study are presented in Table 1. A sample size of 25 patients was calculated to detect a mean difference of $1( \pm 1.25)$ point with $80 \%$ power and a equals 0.05 .

\section{Tooth Preparation}

Selected teeth were prepared for a metal-ceramic restoration (shoulder bevel finishing line on the buccal and a chamfer finishing line on the lingual surface) following standard procedure ${ }^{30}$ under local anesthesia (lidocaine $2 \%+$ epinephrine 1/100000). No effort was done to remove or alter the smear layer. After tooth preparation and impression taking, 3\% potassium nitrate (Kimia, Tehran, Iran) was applied to one randomly selected abutment teeth and Fluoride varnish (Bifluride 10, VOCO, Germany) was applied on another randomly selected abutment according to the manufacturers' recommendations, while only sterile saline was applied on the third abutment using cotton brush (control group). Randomization was done using permuted blocks (by A.A). The teeth number and allocated group were recorded, and the patient did not know the type of material used for each tooth.

\section{FPD Cementation}

Following tooth preparation and impression taking, an acrylic resin temporary restoration (ALIKE, GC, USA) was made and cemented (TempBond, Kerr, Germany) in all cases. PFM restoration was fabricated in the school laboratory by experienced technicians.
Table 1: Inclusion criteria

\begin{tabular}{l}
\hline Inclusion criteria \\
\hline - Patients who at least had three vital teeth in need of fixed \\
prosthesis restorations. \\
- The selected teeth should not be adjacent. \\
- Healthy patients (ASA I and II) who does not require the use of \\
prophylactic antibiotics or complementary steroids. \\
- Age range of 30-50 \\
- No sensitivity to substances used during the experiment. \\
- No hypersensitivity of the teeth \\
- No use of anti-histamine, anti-inflammatory, analgesic, and \\
opioid drugs. \\
- Not pregnant \\
- No periodontitis disease or history of periodontal treatment \\
history \\
- No extensive caries in the abutments \\
remain following tooth preparation in the abutments \\
\hline Exclusion criteria
\end{tabular}

- Subjects who did not participate in the follow-up sessions

- Subjects who consumed painkillers between and/or before follow-up sessions

The manufactured frame was tried in after about one week and the final restoration was cemented (resin-modified glass ionomer luting cement, GC Corp, Tokyo, Japan) after about two weeks.

\section{Sensitivity Test}

First, the adjacent teeth were protected and isolated by dental gauze. A blind examiner evaluated teeth sensitivity. Tooth hypersensitivity was determined by using the air-water syringe of a dental unit to blow air on the buccal surface of a tooth from a distance of $1 \mathrm{~cm}$ for 1 minute. The degree of sensitivity was measured using a McGill visual analog scale (VAS) from 1 to 10 . The VAS is a ruler $10 \mathrm{~cm}$ in length with the left-side end representing complete painlessness (0) and the right-side end representing the worst pain imaginable. Following stimulation of the tooth with a blast of air, the subjects selected a number on the VAS ruler indicating the degree of pain they experienced. The VAS is considered reliable as the amount of pain in one patient is measured multiple times (at least twice) and the results of each test for that individual compares favorably. The first sensitivity measurement was done before injection and preparation and those teeth which were sensitive were excluded. Abutment teeth sensitivity was measured at five different time points. First, it was assumed that after two hours local anesthesia would lose its effect. Hence, baseline measurement was done 2 hours (before temporary crown cementation) after preparation. Also, tooth sensitivity was measured 7 (frame try in session) days after preparation, just before permanent cementation, after permanent cementation and oneweek post cementation. In the first three time points, tooth sensitivity was measured on the prepared abutment while the temporary crown was not cemented on the tooth.

\section{Statistical Analysis}

To compare the rate of sensitivity between three groups, potassium nitrate, and fluoride varnish and control, Kruskal-Wallis test was used. For comparing sensitivity between different times, Friedman statistical test followed by Wilcoxon was used. Statistical analysis was performed by statistical package for social sciences version 21 (SPSS, Chicago, IL) at a significance level of 0.05 . 
Desensitizers After Crown Preparation

Table 2: The rate of sensitivity assessed by VAS in three groups at five different time points (sample size $=100$ in each group)

\begin{tabular}{|c|c|c|c|c|}
\hline \multirow[t]{2}{*}{ Time point } & \multicolumn{2}{|c|}{ Test groups } & \multirow[b]{2}{*}{ Control group } & \multirow[b]{2}{*}{$p$ value } \\
\hline & Potassium nitrate & Fluoride varnish & & \\
\hline Baseline & $6.96 \pm 2.67$ & $6.32 \pm 2.71$ & $7.01 \pm 2.98$ & 0.089 \\
\hline 7 days after preparation & $5.67 \pm 2.67$ & $5.19 \pm 2.698$ & $6.17 \pm 2.87$ & $<0.001$ \\
\hline Before cementation & $4.75 \pm 2.83$ & $4.12 \pm 2.82$ & $5.68 \pm 2.96$ & 0.002 \\
\hline After cementation & $1.34 \pm 1.14$ & $1.87 \pm 1.65$ & $2.64 \pm 2.04$ & 0.001 \\
\hline 7 days after cementation & $0.25 \pm 0.70$ & $0.55 \pm 1.06$ & $1.21 \pm 2.83$ & $<0.001$ \\
\hline
\end{tabular}

\section{Results}

This study was performed on 300 vital abutment teeth needed full crown coverage in 100 patients (69 females and 31 males) who met the inclusion criteria. The mean age of the patients was $43.52 \pm 12.91$ years old. All included patients participated in follow-up sessions, and there was no withdrawal.

The mean VAS score indicating tooth sensitivity in the three groups is presented in Table 2. Before preparation, all teeth had no sensitivity. Tooth sensitivity was significantly lower in potassium nitrate and fluoride varnish groups compared to control group $(p<0.05)$; except at baseline measurement which all teeth showed high sensitivity, and there was no significant difference between three groups ( $p=0.089$ ). Comparison of potassium nitrate and fluoride varnish shows no significant difference between these two groups ( $p>0.05)$; except one week after permanent cementation at which potassium nitrate reduced sensitivity more than fluoride varnish $(p=0.023)$.

Tooth sensitivity was reduced significantly in all three groups just before cementation compared to baseline $(p<0.05)$. In addition, cementation resulted in a reduction of sensitivity as shown by VAS at post-cementation and one week after cementation compared to all pre-cementation phases $(p<0.05)$ (Graph 1).

No correlation was found between patient age and VAS score in three groups at different time points $(p>0.05)$. In addition, the sensitivity reported by men and women was not significantly different $(p>0.05)$.

An accidental finding was the immediate pain after use of fluoride varnish followed by air spray which was not reported in other groups.

\section{Discussion}

Tooth sensitivity occurs sometimes due to tooth preparation for fix prosthesis, which happens is due to exposure of dentin tubules and would patient discomfort and pain. The aim of the current study was to evaluate the short-term efficacy of fluoride varnish and potassium nitrate in the reduction of crown preparation tooth sensitivity. The results demonstrated that both desensitizing agents could decrease tooth sensiti vity during fabrication of FPD and one week after permanent cementation compared to the control group.

Previously Jalalian et al. ${ }^{31}$ demonstrated the effectiveness of potassium nitrate in the reduction of post preparation tooth sensitivity compared to Gluma and control groups during precementation treatment phases. The current study confirmed the results of the previous study with the same methodology and showed that potassium nitrate is also effective in the reduction of post cementation sensitivity. The sensitizing effect of potassium nitrate may be associated with an increase in the concentration of extracellular potassium around the nerve fiber, which affects

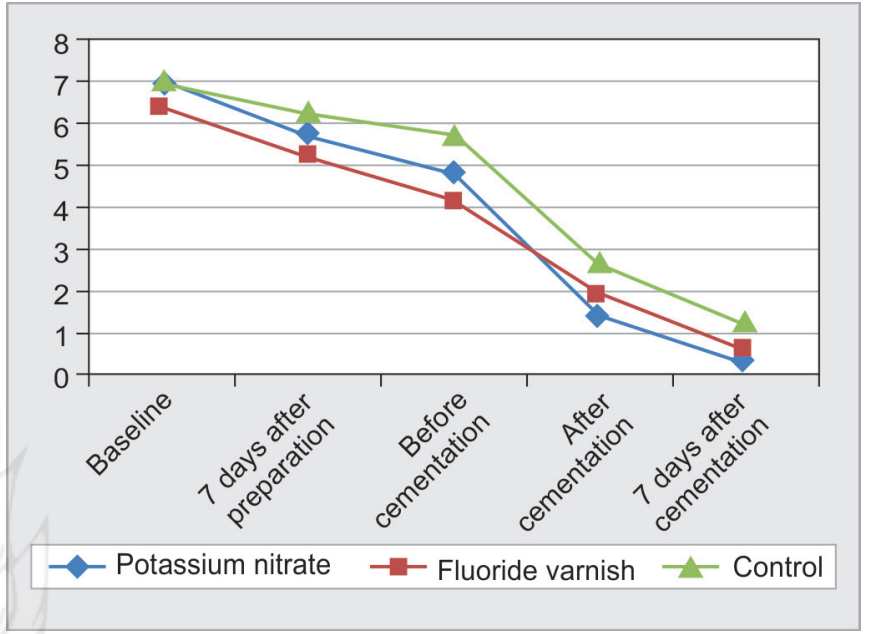

Graph 1: The rate of sensitivity assessed by VAS in three groups at five different time points

their depolarization, avoid repolarization and blocks the axonic action. This blocks the passage of nerve stimulus and results in inactivation of its action potential. ${ }^{16,32}$ The average concentration of potassium ions around the nerves is $4 \mathrm{mmol} / \mathrm{L}$. When it rises up to $8 \mathrm{mmol} / \mathrm{I}$ or higher, the $A$ beta and $A$ delta and $C$ nerve fibers become depolarized. Complete nerve block occurs at $32 \mathrm{mmol} / \mathrm{L}$ potassium ion. When potassium salts are applied on the outer surface of the dentin, potassium ions pass through the tubules to achieve $8 \mathrm{mmol} / \mathrm{L}$ or more concentrations in the fluid surrounding the nerves. This increase of potassium ion concentration should remain at this level in order to hold the deactivation of dental nerves continuously. ${ }^{16,33}$ However, potassium nitrate does not occlude dentinal tubules. ${ }^{2}$

Desensitizing effect of fluoride differs from potassium nitrate. Fluoride varnish mainly acts by its ability to form calcium fluoride nuclei ${ }^{34}$ and, to some extent, by the formation of fluoroapatite, thus blocking the transmission of stimuli to the pulp. ${ }^{20,21}$ In a study done by Shen and Autio-Gold, ${ }^{35}$ it was found that after fluoride application, a significant elevation of fluoride level in the whole saliva occurs. Due to the presence of a significant amount of fluoride in saliva, high fluoride uptake in the surface and subsurface layer happens. ${ }^{36}$ This might influence the desensitizing features of fluoride.

To the extent of our knowledge, this was the first report compared the efficacy of potassium nitrate and fluoride varnish in the reduction of FPD preparation hypersensitivity and the results showed that none of them had any superiority in decreasing pain and sensitivity before cementation. However, one week after cementation desensitizing effect of potassium nitrate was more prominent than fluoride varnish. In addition, it was noticeable 
that following the application of fluoride varnish in some cases, very high sensitivity was reported. It could cause sensitivity and discomfort that is associated with a sharp and long-term pain, which is probably caused by cooling of the tooth due to solvent evaporation. This could be considered as a side effect of fluoride varnish. A solvent such as ethanol influence adhesion properties of varnish and diffusion of fluoride ions into the hydroxylapatite crystal structure.

In contrast to the results of the current study, Yadav et al. ${ }^{37}$ reported higher dentin hypersensitivity in women compared to men following tooth preparation for FPD. The current study showed no gender difference which might be due to smaller sample size compared to the mentioned study which studied hypersensitivity in 124 subjects.

One of the limitations of the current RCT was short follow-up. However, seven days after cementation of FPD the patients experienced low sensitivity. Although longer follow-ups could result in a further reduction in VAS scores, the difference between groups might not be clinically significant. The other limitation of this study was that the effect of desensitizing materials on the long-term vitality of the tooth was not evaluated. Further studies are necessary to evaluate this effect.

\section{Conclusion}

Within the limitations of this study, it could be concluded that potassium nitrate and fluoride varnish could reduce tooth sensitivity following crown preparation. Both materials had relatively similar effects before permanent cementation while potassium nitrate reduced post cementation tooth sensitivity more than fluoride varnish. In addition, minor discomfort was observed in a few patients treated with fluoride varnish.

\section{Clinical significance}

Both potassium nitrate and fluoride varnish are capable of desensitizing prepared tooth for the fixed partial denture. In the short term, potassium nitrate can more effectively reduce tooth sensitivity.

\section{References}

1. Consensus-based recommendations for the diagnosis and management of dentin hypersensitivity. J Can Dent Assoc 2003;69(4):221-226.

2. Salian, S, Thakur S, Kulkarni S, et al. A randomized controlled clinical study evaluating the efficacy of two desensitizing dentifrices. J Clin Dent 2010;21(3):82-87.

3. Tammaro, S, Wennstrom JL, Bergenholtz G. Root-dentin sensitivity following non-surgical periodontal treatment. J Clin Periodontol 2000;27(9):690-697.

4. West, N, Seong J, Davies M. Dentine hypersensitivity. Monogr Oral Sci 2014;25108-122.

5. Camps, J, About I, Gouirand S, et al. Dentin permeability and eugenol diffusion after full crown preparation. Am J Dent 2003;16(2):112-116.

6. Pihlaja, J, Napankangas R, Raustia A. Early complications and shortterm failures of zirconia single crowns and partial fixed dental prostheses. J Prosthet Dent 2014;112(4):778-783.

7. Jackson, CR, Skidmore AE, Rice RT. Pulpal evaluation of teeth restored with fixed prostheses. J Prosthet Dent 1992;67(3):323-325.

8. Morad, G, Behnia H, Motamedian SR, Shahab S, Gholamin P, Khosraviani K, et al. Thickness of labial alveolar bone overlying healthy maxillary and mandibular anterior teeth. J CraniofacSurg 2014;25(6):1985-1991.

9. Behnia, H, Motamedian SR, Kiani MT, et al. Accuracy and reliability of cone beam computed tomographic measurements of the bone labial and palatal to the maxillary anterior teeth. Int J Oral Maxillofac Implants 2015;30(6):1249-1255.
10. Safari S, Mahdian A, Motamedian SR. Applications of stem cells in orthodontics and dentofacial orthopedics: Current trends and future perspectives. World J Stem Cells 2018;10(6):66-77.

11. Khojasteh, A, Motamedian SR, Sharifzadeh N, et al. The influence of initial alveolar ridge defect morphology on the outcome of implants in augmented atrophic posterior mandible: an exploratory retrospective study. Clin Oral Implants Res 2017;28(10): e208-e217.

12. Khodadadi E, Mohammadpour M, Motamedian SR, et al. Failure Rate of Pediatric Dental Treatment under General Anesthesia. Dent J (Basel) 2018;6(3):E25.

13. Stern MA, Brudvik JS, Frank RP. Clinical evaluation of removable partial denture rest seat adaptation. J Prosthet Dent 1985;53(5): 658-662.

14. Pashley DH. Dentin permeability, dentin sensitivity, and treatment through tubule occlusion. J Endod 1986;12(10):465-474.

15. Kerns, DG, Scheidt MJ, Pashley DH, et al. Dentinal tubule occlusion and root hypersensitivity. J Periodontol 1991;62(7):421-428.

16. Peacock JM, Orchardson R. Effects of potassium ions on action potential conduction in A- and C-fibers of rat spinal nerves. J Dent Res 1995;74(2):634-641.

17. Orchardson R, Gillam DG. The efficacy of potassium salts as agents for treating dentin hypersensitivity. J Orofac Pain 2000;14(1):9-19.

18. Jacobsen PL, Bruce G. Clinical dentin hypersensitivity: understanding the causes and prescribing a treatment. J Contemp Dent Pract 2001;2(1):1-12.

19. Shetty R, Bhat AN, Mehta D, et al. Effect of a Calcium Phosphate Desensitizer on Pre- and Postcementation Sensitivity of Teeth Prepared for Full-Coverage Restorations: A Randomized, PlaceboControlled Clinical Study. Int J Prosthodont 2017;30(1):38-42.

20. Nagata $\mathrm{T}$, Ishida $\mathrm{H}$, Shinohara $\mathrm{H}$, et al. Clinical evaluation of a potassium nitrate dentifrice for the treatment of dentinal hypersensitivity. J Clin Periodontol 1994;21(3):217-221.

21. Pereira, JC, Martineli AC, Tung MS. Replica of human dentin treated with different desensitizing agents: a methodological SEM study in vitro. Braz Dent J 2002;13(2):75-85.

22. Tzanova, S, Ivanova Z, Velinova S. Clinical evaluation of dentinal hypersensitivity treatment with $5 \%$ potassium nitrate dentifrice. Folia Med (Plovdiv) 2005;47(2):65-69.

23. Sheykhzade M, Berg Nyborg NC. Mechanism of CGRP-induced relaxation in rat intramural coronary arteries. $\mathrm{Br} J$ Pharmacol 2001;132(6):1235-1246.

24. Merika K, HeftitArthur F, Preshaw PM. Comparison of two topical treatments for dentine sensitivity. Eur J ProsthodontRestor Dent 2006;14(1):38-41.

25. Chu CH, Lo E. Uses of sodium fluoride varnish in dental practice. Ann R AustralasColl Dent Surg 2008;1958-1961.

26. Karim, BF, Gillam DG. The efficacy of strontium and potassium toothpastes in treating dentine hypersensitivity: a systematic review. Int J Dent 2013;2013573258.

27. Hooshmand B, Alavian SM, Kouhestani F, et al. Detection of Hepatitis C Virus RNA in Blood and Saliva of Transfusion-Dependent Thalassemia Patients Diagnosed with Hepatitis C. Contemp Clin Dent 2018;9(1): 5-9.

28. Tehranchi A, Motamedian SR, Saedi S, et al. Correlation between frontal sinus dimensions and cephalometric indices: A cross-sectional study. Eur J Dent 2017;11(1):64-70.

29. Eslamipour F, Motamedian SR, Bagheri F. Ibuprofen and Low-level Laser Therapy for Pain Control during Fixed Orthodontic Therapy: A Systematic Review of Randomized Controlled Trials and Metaanalysis. J Contemp Dent Pract 2017;18(6):527-533.

30. Shillingburg HT, Hobo $S$, Whitsett LD, et al. Fundamentals of Fixed Prosthodontics. Quintessence Publishing Co, Inc, IL. 2012;455-484.

31. Jalalian, E, Meraji N, Mirzaei M. A comparison of the efficacy of potassium nitrate and Gluma desensitizer in the reduction of hypersensitivity in teeth with full-crown preparations. J Contemp Dent Pract 2009;10(1):66-73.

32. Markowitz, K, Bilotto G, Kim S. Decreasing intradental nerve activity in the cat with potassium and divalent cations. Arch Oral Biol 1991;36(1):1-7.

33. Frechoso SC, Menendez M, Guisasola C, et al. Evaluation of the efficacy of two potassium nitrate bioadhesive gels ( $5 \%$ and $10 \%$ ) in the treatment 
of dentine hypersensitivity. A randomised clinical trial.J Clin Periodontol 2003;30(4):315-320.

34. Brannstrom $\mathrm{M}$, Nyborg $\mathrm{H}$. Pulp reaction to fluoride solution applied to deep cavities: an experimental histological study. J Dent Res 1971;50(6):1548-1552.

35. Shen C, Autio-Gold J. Assessing fluoride concentration uniformity and fluoride release from threevarnishes.J Am Dent Assoc 2002;133(2):176-182.
36. Ehrlich J, Hochman N, Gedalia I, et al. Residual fluoride concentrations and scanning electron microscopic examination of root surfaces of human teeth after topical application of fluoride in vivo. J Dent Res 1975;54(4):897-900.

37. Yadav, K, Sofat A, Gambhir RS, et al. Dentin hypersensitivity following tooth preparation: A clinical study in the spectrum of gender. J Nat SciBiol Med 2014;5(1):21-24. 